http://dx.doi.org/10.32929/2446-8355.2019v28n3p316-328

\title{
DESEMPENHO DE GENÓTIPOS DE FEIJÃO COMUM NO PERÍODO DE OUTONO-INVERNO EM REGIÃO DE CERRADO DE BAIXA ALTITUDE
}

Tayná Lara Serantoni da Silveira ${ }^{1}$, Natasha Mirella Inhã Godoi ${ }^{2}$, Leticia Zylmennith de Souza Sales ${ }^{2 *}$, Lucas Martins Garé ${ }^{2}$, Marcio Akira Ito ${ }^{3}$, Orivaldo Arf ${ }^{4}$

\footnotetext{
${ }^{1}$ Engenheira Agrônoma, Engenharia Agronômica, Faculdade de Engenharia da UNESP, Ilha Solteira, São Paulo.

${ }^{2}$ Mestrando, Programa de Pós-graduação em Agronomia, Faculdade de Engenharia da UNESP, Ilha Solteira, São Paulo. *E-mail do autor correspondente: 1.zylmennith@ hotmail.com.

${ }^{3}$ Pesquisador científico, Sistemas sustentáveis, Embrapa Agropecuária Oeste, Dourados, Mato Grosso do Sul.

${ }^{4}$ Docente, Professor titular do departamento de Fitotecnia, Tecnologia de Alimentos e Sócio Economia, Faculdade de Engenharia da UNESP, Ilha Solteira, São Paulo.
}

Recebido: 05/11/2018; Aceito: 30/08/2019

RESUMO: O feijoeiro é produzido em todas as regiões do território brasileiro, submetido à diversas condições climáticas e manejos e, em função disto, busca-se cultivares que apresentem elevada produtividade e adaptação ao local de cultivo. Posto isso, o objetivo do trabalho foi verificar o desempenho de diferentes genótipos de feijão comum, no período de outono-inverno em região de cerrado de baixa altitude em dois anos consecutivos. $\mathrm{O}$ delineamento experimental utilizado foi o de blocos casualizados com 17 tratamentos, sendo 13 cultivares e 4 linhagens elites, com três repetições. Os genótipos CNFC 10762, CNFC 10729 e CNFP 10794, apresentaram bom comportamento na região, nos dois anos de cultivo, com boa perspectiva de serem lançados como novos cultivares. A instabilidade para a doença antracnose no cultivar TAA Bola Cheia desaconselha a utilização do mesmo na região estudada. A presença de interação genótipo x ambiente indica a necessidade a avaliação dos genótipos em vários anos e locais.

Palavras-chave: Phaseolus vulgaris L. Linhagens elites. Teste de adaptação local.

\section{PERFORMANCE OF COMMON BEAN GENOTYPES IN FALL-WINTER SEASON IN SAVANNAH REGION WITH LOW ALTITUDE}

\begin{abstract}
The beans is grown in several regions of Brazil, under different climatic conditions and management and, this is due, search for cultivars with show yield and adaptation to the growth's place. Put it, the aim of study was inspect the performance and agronomic efficiency of different genotypes of common bean, at the fall-winter season in Selviria - MS for two consecutive years. A randomized complete block design was used with 17 treatments, being 13 cultivars and 4 elite lines, with three replications. The genotypes CNFC 10762, CNFC 10729 e CNFP 10794, showed good behavior in the region during at two years of cultivation, with good prospect of being introduced as new cultivars. Instability for the disease Antracnose in the cultivar TAA Bola Cheia advises against the use of the same
\end{abstract}


in the worked region. The presence of genotype $\mathrm{x}$ environment interaction indicates the need to evaluate the genotypes in several years and local.

Key words: Phaseolus vulgaris L. Elite lines. Local adaptation test.

\section{INTRODUÇÃO}

Entre os diversos tipos de grãos, o feijão é uma cultura que apresenta papel relevante na agricultura brasileira, principalmente nas regiões Norte e Nordeste, visto que além do fator econômico, apresenta alto grau de importância social em função de a agricultura familiar ser detentora da maior parcela produtiva e ser uma fonte de proteína de baixo custo (EMPRESA BRASILEIRA DE PESQUISA AGROPECUÁRIA - EMBRAPA, 2013).

O feijoeiro comum, no Brasil, é cultivado em três diferentes safras e em distintas regiões do território brasileiro, por isso submetido aos diversificados sistemas produtivos, condições climáticas (PEREIRA et al., 2009), além de níveis tecnológicos. Contudo, é importante salientar que, alguns fatores climáticos como temperatura, precipitação pluviométrica e radiação solar podem influenciar na produtividade, assim como exposição à temperaturas muito baixas e geadas. Vieira (2006) destaca que, diferentes comportamentos em um mesmo genótipo podem ser detectados em função de distintas localidades, logo, uma recomendação adequada em função de programas de melhoramento genético, deve levar em consideração, também, as interações genótipo x ambiente (ALLARD; BRADSHAW, 1964; COIMBRA et al., 2008).

Dada sua importância e sensibilidade a fatores biótico e abióticos, busca-se tecnologias que viabilizem o aumento de produtividade e, dentre estas, não apenas o suporte de maquinário agrícola, mas também técnicas de cultivo, aporte hídrico e qualidade e potencial genético de sementes. Por conseqüência, os programas de melhoramento genético têm disponibilizado ao mercado agrícola cultivares que apresentem características desejáveis de produção e, desta forma, contribuído diretamente para o aumento da produtividade brasileira que, em 1997 girava em torno de $749 \mathrm{~kg} \mathrm{ha}^{-1}$, e atualmente está estipulada em média $1.043 \mathrm{~kg}$ ha $^{-1}$ (PEREIRA, et al. 2013; COMPANHIA NACIONAL DE ABASTECIMENTO CONAB, 2018)

A Embrapa Arroz e Feijão, coordenadora do Programa Nacional de Melhoramento de Feijão, visa às linhagens com características agronômicas superiores como, por exemplo, arquitetura mais ereta, alta produtividade, resistência a estresses bióticos e abióticos, precocidade, entre outras características (SOUZA, et al. 2013). Dessa forma entre 1984 e 2004, de 111 novas cultivares lançadas, a Embrapa Arroz e Feijão foi responsável pela elaboração de 32 cultivares, de diversos tipos comerciais de grão, uma média de 1,6 cultivar por ano (MELO et al., 2007).

Ainda assim, há certa dificuldade na realização, com sucesso, do melhoramento genético para uma recomendação precisa, pois como supracitado, há uma heterogeneidade no território brasileiro, visto que inserido em condições tropicais há uma menor estabilidade de clima e solo, além de incluir preferências regionais e disponibilidade de recursos por parte do produtor (CARNEIRO, 2002). 
Portanto, é notório, a relevância da identificação de cultivares responsivas a determinadas localidades e com maior estabilidade fenotípica, visando a redução dos efeitos da interação genótipo x ambiente, tornando a recomendação agrícola de cultivar mais segura e confiável ao produtor.

Tendo em vista a seleção de cultivares melhores adaptadas à região e que apresentem alto potencial produtivo, o trabalho teve como objetivo avaliar o potencial de desempenho e eficiência agronômica de diferentes genótipos do feijão comum, no período de outonoinverno em região de baixa altitude em dois anos consecutivos.

\section{MATERIAL E MÉTODOS}

O trabalho, em parceria com a EMBRAPA, foi desenvolvido em área experimental pertencente à Faculdade de Engenharia - UNESP, Campus de Ilha Solteira, localizada no município de Selvíria (MS) nos anos de 2014 e 2015, apresentando coordenadas geográficas $51^{\circ} 22^{\prime}$ de longitude Oeste de Greenwich e $20^{\circ} 22^{\prime}$ de latitude Sul, com altitude de 335 metros. O solo do local é do tipo LATOSSOLO VERMELHO Distrófico típico argiloso, A moderado, hipodistrófico, álico, muito profundo e moderadamente ácido (EMBRAPA, 2013). A precipitação média anual é de $1.370 \mathrm{~mm}$, a temperatura média anual é de $23,5^{\circ} \mathrm{C}$ e a umidade relativa do ar entre 70 e $80 \%$ (média anual).

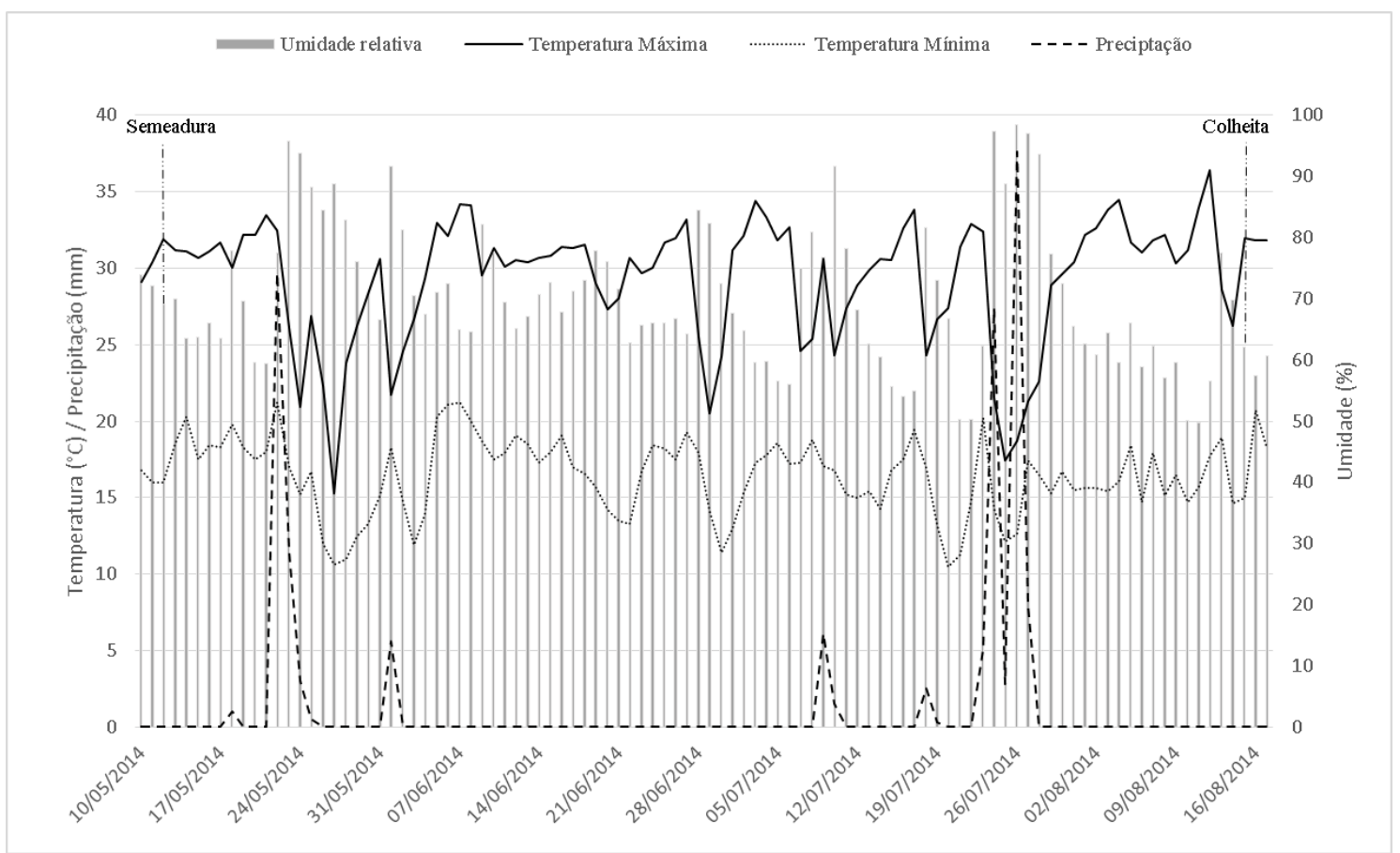

Figura 1. Variação diária de precipitação, umidade relativa e temperatura máxima e mínima do ar durante o período de maio a agosto de 2014. Daily variation of precipitation, relative humidity and maximum and minimum air temperature during the period from May to August 2014. 


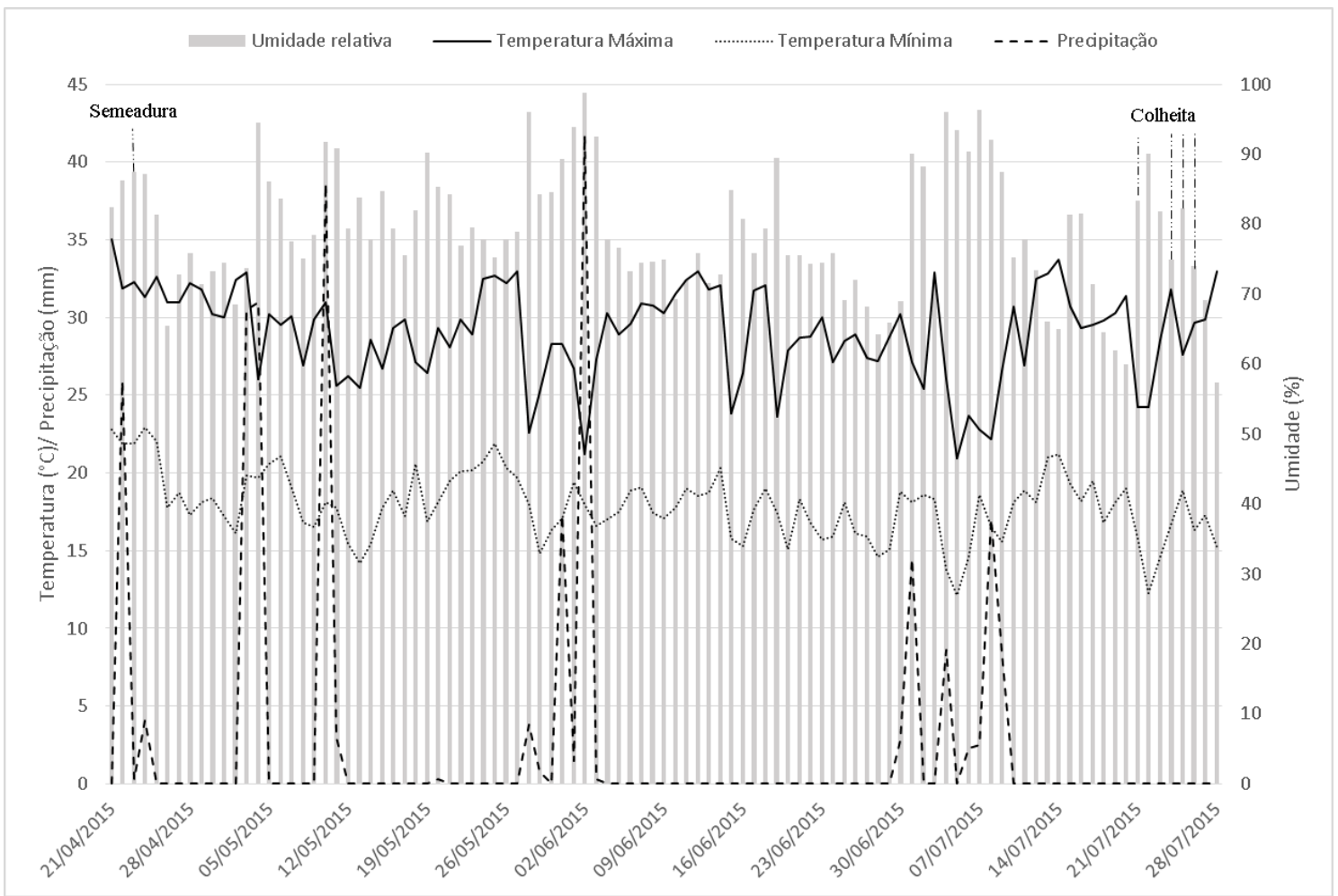

Figura 2. Variação diária de precipitação, umidade relativa e temperatura máxima e mínima do ar durante o período de abril a julho de 2015. Daily variation of precipitation, relative humidity and maximum and minimum air temperature during the period from April to July 2015.

O delineamento experimental foi o de blocos casualizados, com 17 tratamentos, constituídos por diferentes genótipos de feijão-comum, com três repetições. Foram utilizados os seguintes genótipos: Pérola, BRS Estilo, BRS Notável, BRS Ametista, BRSMG Madrepérola, TAA Bola Cheia, BRS Esteio, BRS Campeiro, BRS Esplendor, IAC Diplomata, IAPAR 81, IAC Alvorada, IPR Tangará, sendo estes cultivares já registrados e, CNFC 10429, CNFC 10762, CNFC 10729, CNFP 10794, linhagens elite. As parcelas experimentais foram constituídas por quatro linhas de $4 \mathrm{~m}$ de comprimento com espaçamento nas entrelinhas de $0,50 \mathrm{~m}$.

O fornecimento de água, quando necessário, foi realizado por um sistema fixo de irrigação convencional por aspersão com precipitação média de $3,3 \mathrm{~mm}$ hora $^{-1}$ nos aspersores. Os tratos culturais e fitossanitários utilizados foram os normalmente recomendados à cultura do feijão "de inverno" para a região.

As características químicas do solo foram determinadas antes da instalação do experimento, seguindo a metodologia proposta por Raij et al. (2001). A adubação mineral básica foi realizada levando-se em consideração as características químicas do solo e as recomendações de Ambrosano et al. (1996).

No primeiro ano a semeadura foi realizada no dia 12/05/2014 e a colheita em 12 e $15 / 08 / 2014$. No segundo ano, a semeadura ocorreu no dia 23/04/2015 e a colheita ocorreu nos dias 21, 24, 25 e 26/07/2015. As colheitas dos dois anos foram realizadas em vários dias devido à diferença de ciclo presente entre os genótipos. 
Tabela 1. Resultados da análise química do solo na profundidade de $0-0,20 \mathrm{~m}$, antes da implantação do experimento, Selvíria - MS, 2014 e 2015. Results of soil chemical analysis in the depth of $0-0.20 m$, before the implementation of the experiment, Selviria - MS, 2014 and 2015.

\begin{tabular}{|c|c|c|c|c|c|c|c|c|c|}
\hline \multirow{2}{*}{ Ano } & \multirow{2}{*}{$\begin{array}{c}P \\
\mathrm{mg} \mathrm{dm}^{-3}\end{array}$} & \multirow{2}{*}{$\begin{array}{l}\text { M.O. } \\
\text { g dm}^{-3}\end{array}$} & \multirow{2}{*}{$\begin{array}{c}\mathbf{p H} \\
\mathrm{CaCl}_{2}\end{array}$} & $\mathbf{K}$ & Ca & Mg & $\mathbf{H}+\mathbf{A l}$ & CTC & \multirow{2}{*}{$\begin{array}{c}\mathrm{V} \\
(\%)\end{array}$} \\
\hline & & & & \multicolumn{5}{|c|}{ mmolc dm dm $^{-3}$} & \\
\hline 2014 & 11 & 19 & 5,0 & 0,8 & 14 & 14 & 31 & 59,8 & 48 \\
\hline 2015 & 33 & 21 & 5,3 & 3,4 & 20 & 13 & 34 & 70,4 & 52 \\
\hline
\end{tabular}

Foram realizadas as seguintes avaliações nos dois anos referentes ao trabalho: Ciclo determinado o número de dias transcorridos entre emergência e o dia de colheita; Florescimento pleno - determinado o número de dias transcorridos entre emergência e o florescimento pleno, ou seja, quando 50\% das flores dos genótipos estavam abertas; Número de vagens por planta - obtido pela contagem do número de vagens por planta, considerandose uma amostra de 8 plantas por parcela; Número de grãos por planta - obtido pela contagem do número de grãos por planta, considerando-se uma amostra de 8 plantas por parcela; Número de grãos por vagem - Obtido pela relação número de grãos/número de vagens, considerando-se uma amostra de 8 plantas por parcela; Massa de 100 grãos determinada pesando-se em balança de precisão 2 amostras de 100 grãos retiradas de cada parcela colhida, corrigindo-se posteriormente a umidade para $13 \%$ - base úmida; Produtividade de grãos - foram colhidas as plantas da área útil de cada parcela e após terem sido secas a pleno sol, foram submetidas à trilha manual, pesando os grãos em seguida e transformando-os em $\mathrm{kg} \mathrm{ha}^{-1}$ (13\% base úmida), de acordo com BRASIL (1980), cuja fórmula é representada em: $\mathrm{F}=\mathrm{I}(100-\mathrm{U} 1$ )/(100-U2 ), onde $\mathrm{F}=$ produção de sementes com a umidade desejada (13\%); I = produção de sementes com a umidade inicial; U1 = umidade inicial das sementes.

Para a avaliação de dados utilizou-se do programa estatístico SISVAR. Pela análise de variância e pelo teste de Skott-Knott em nível de 6\% de probabilidade, foi possível notar a diferença entre os genótipos envolvidos.

\section{RESULTADOS E DISCUSSÃO}

A emergência das plântulas ocorreu nos dias 17/05/2014 e 29/04/2015, aos cinco e seis dias após a semeadura, respectivamente. Os resultados obtidos dos caracteres que passaram por análise, estão apresentados nas Tabelas 2, 3 e 4.

Pelo teste de agrupamento de Scott-Knott nota-se na Tabela 2, que no primeiro ano houve variação significativa relacionada ao ciclo dos genótipos. Estes variaram de 77 a 83 dias após a emergência, logo considerados semiprecoces. BRS Notável revelou-se como o cultivar mais precoce (77 dias), seguido pela BRS Campeiro e IAC Alvorada com ciclos de 79 dias.

No segundo ano os ciclos variaram de 85 a 87 dias após a emergência, portanto considerados normais, não havendo uma variação significativa. 
Tabela 2. Ciclos dos diferentes genótipos de feijão comum. Selvíria - MS, 2014 e 2015. Cycles of the different common bean genotypes. Selviria-MS, 2014 and 2015.

\begin{tabular}{ccc}
\hline Tratamentos & \multicolumn{2}{c}{ Ciclo } \\
\hline Genótipos & 2014 & 2015 \\
\hline BRS Ametista & $83 \mathrm{a}$ & 85 \\
BRS Campeiro & $79 \mathrm{~b}$ & 85 \\
BRS Esplendor & $83 \mathrm{a}$ & 86 \\
BRS Esteio & $82 \mathrm{a}$ & 85 \\
BRS Estilo & $81 \mathrm{a}$ & 85 \\
BRS Notável & $77 \mathrm{c}$ & 85 \\
BRSMG Madrepérola & $80 \mathrm{~b}$ & 86 \\
IAC Alvorada & $79 \mathrm{~b}$ & 86 \\
IAC Diplomata & $83 \mathrm{a}$ & 85 \\
IAPAR 81 & $83 \mathrm{a}$ & 85 \\
IPR Tangará & $83 \mathrm{a}$ & 85 \\
Pérola & $83 \mathrm{a}$ & 85 \\
TAA Bola Cheia & $82 \mathrm{a}$ & 85 \\
CNFC 10429 & $83 \mathrm{a}$ & 87 \\
CNFC 10729 & $83 \mathrm{a}$ & 86 \\
NFC 10762 & $82 \mathrm{a}$ & 85 \\
CNFP 10794 & $83 \mathrm{a}$ & 86 \\
\hline Teste F & $9,347 * *$ & $1,00^{\mathrm{ns}}$ \\
\hline CV $(\%)$ & 1,29 & 1,31 \\
\hline
\end{tabular}

Médias seguidas de mesma letra, dentro de cada safra estudada, não diferem entre si pelo teste de Scott-Knott a $6 \%$ de probabilidade. $*{ }^{*},=$ significativo a $6 \%$ e $1 \%$ de probabilidade pelo teste de Scott-Knott, respectivamente; $\mathrm{NS}=$ não significativo; $\mathrm{CV}=$ coeficiente de variação. Means followed by the same letter, within each crop studied, do not differ among themselves by the Scott-Knott test at $6 \%$ probability. *, ** = significant at $6 \%$ and $1 \%$ probability by the Scott-Knott test, respectively; NS = not significant; $C V=$ coefficient of variation.

De acordo com o catálogo 2016/17 de cultivares de feijão comum da EMBRAPA, o cultivar BRS Notável apresenta um ciclo de 75-84 dias, tido como semiprecoce, corroborando os resultados obtidos no primeiro ano (77 dias) e aproximando-se no segundo ano ( 85 dias). $\mathrm{O}$ mesmo ocorre com o cultivar BRS Campeiro, considerado, também, como semiprecoce (75 a 84 dias), e cujo ciclo foi de 79 e 85 dias, respectivamente, no presente trabalho.

Os cultivares BRS Ametista, BRS Esplendor, BRS Estilo, Pérola e BRSMG Madrepérola, tratando-se os quatro primeiros de cultivares de ciclos normais (85-95) e o último semiprecoce, contradizem, em partes, às informações indicadas no catálogo da EMBRAPA, visto que apenas o resultado de um dos anos corrobora a informação disponibilizada.

De acordo com o Instituto Agronômico do Paraná (IAPAR), o cultivar IPR Tangará apresenta ciclo médio de 87 dias, diferindo-se dos resultados obtidos no presente trabalho no primeiro e segundo ano, 83 e 85 dias, respectivamente. O cultivar IAPAR 81 expôs o ciclo 
mais divergente às informações fornecidas pelo IAPAR (aproximadamente 92 dias), dado que os resultados obtidos foram de 83 e 85 dias. Assim como o cultivar IAC Diploma que, obteve ciclos de 83 e 85 dias, enquanto que o Instituto agronômico de Campinas indica 90 dias.

Comparadas ao cultivar testemunha Pérola, as linhagens testadas CNFC 10729, CNFP 10794, CNFC 10762, CNFC 10429 não apresentaram uma discrepância relevante em relação ao ciclo. E, no que se refere ao coeficiente de variação (CV \%), que se apresentam 1,29\% e $1,31 \%$, diz-se que são precisos e coerentes, não corroborando dispersão nos dados obtidos.

Na Tabela 3 estão apresentados os valores médios do número de vagens por planta, número de grãos por planta e número de grãos por vagem.

Tabela 3. Valores médios dos componentes de produção dos diferentes genótipos de feijão comum. Selvíria - MS, 2014 e 2015. Average values of yield components of different common bean genotypes. Selvíria - MS, 2014 and 2015.

\begin{tabular}{ccccccc}
\hline Tratamentos & \multicolumn{2}{c}{ Vagem planta $^{-1}$} & \multicolumn{2}{c}{ Grãos planta $^{-1}$} & \multicolumn{2}{c}{ Grãos vagem $^{-1}$} \\
\hline Genótipos & \multicolumn{2}{c}{$\left(\mathrm{n}^{\mathrm{o}}\right)$} & \multicolumn{2}{c}{$\left(\mathrm{n}^{\mathrm{o}}\right)$} & \multicolumn{3}{c}{$\left(\mathrm{n}^{\mathbf{0}}\right)$} \\
\hline BRS Ametista & 2014 & 2015 & 2014 & 2015 & 2014 & 2015 \\
BRS Campeiro & 9,5 & 10,8 & $46,5 \mathrm{~b}$ & 52 & $4,9 \mathrm{a}$ & 4,6 \\
BRS Esplendor & 9,1 & 10,4 & $43,8 \mathrm{~b}$ & 48 & $4,8 \mathrm{a}$ & 4,6 \\
BRS Esteio & 12,2 & 13,8 & $66,3 \mathrm{a}$ & 65 & $5,4 \mathrm{a}$ & 4,8 \\
BRS Estilo & 9,0 & 10,1 & $53,8 \mathrm{a}$ & 46 & $5,9 \mathrm{a}$ & 4,6 \\
BRS Notável & 9,9 & 8,6 & $42,3 \mathrm{~b}$ & 36 & $4,3 \mathrm{~b}$ & 4,1 \\
BRSMG Madrepérola & 8,2 & 12,5 & $29,6 \mathrm{~b}$ & 56 & $4,2 \mathrm{~b}$ & 4,4 \\
IAC Alvorada & 10,1 & 12,6 & $40,1 \mathrm{~b}$ & 57 & $4,9 \mathrm{a}$ & 4,5 \\
IAC Diplomata & 10,3 & 15,1 & $40,9 \mathrm{~b}$ & 52 & $4,1 \mathrm{~b}$ & 3,0 \\
IAPAR 81 & 10,2 & 16,7 & $44,2 \mathrm{~b}$ & 63 & $4,3 \mathrm{~b}$ & 4,2 \\
IPR Tangará & 10,0 & 11,7 & $43,7 \mathrm{~b}$ & 54 & $4,3 \mathrm{~b}$ & 4,5 \\
Pérola & 9,4 & 13,0 & $41,4 \mathrm{~b}$ & 64 & $4,4 \mathrm{~b}$ & 6,1 \\
TAA Bola Cheia & 11,4 & 12,1 & $46,4 \mathrm{~b}$ & 52 & $4,2 \mathrm{~b}$ & 4,2 \\
CNFC 10429 & 8,8 & 12,6 & $42,6 \mathrm{a}$ & 49 & $4,8 \mathrm{a}$ & 6,3 \\
CNFC 10729 & 13,0 & 16,0 & $59,0 \mathrm{~b}$ & 84 & $4,5 \mathrm{~b}$ & 5,3 \\
CNFC 10762 & 10,8 & 11,5 & $55,1 \mathrm{a}$ & 50 & $5,1 \mathrm{a}$ & 4,3 \\
CNFP 10794 & 12,3 & 6,3 & $66,2 \mathrm{a}$ & 32 & $5,4 \mathrm{a}$ & 4,8 \\
\hline Teste F & $1,90^{\mathrm{ns}}$ & $1,58^{\mathrm{ns}}$ & $2,14 *$ & $1,95^{\text {ns }}$ & $3,02 * *$ & $0,72^{\text {ns }}$ \\
\hline CV (\%) & 19,31 & 33,04 & 24,03 & 28,7 & 10,67 & 33,07 \\
\hline
\end{tabular}

Médias seguidas de mesma letra, dentro de cada safra estudada, não diferem entre si pelo teste de Scott-Knott a $6 \%$ de probabilidade. $*{ }^{*} *$ significativo a $6 \%$ e $1 \%$ de probabilidade pelo teste de Scott-Knott, respectivamente; $\mathrm{NS}=$ não significativo; $\mathrm{CV}=$ coeficiente de variação. Means followed by the same letter, within each crop studied, do not differ among themselves by the Scott-Knott test at 6\% probability. *, ** = significant at $6 \%$ and $1 \%$ probability by the Scott-Knott test, respectively; $N S=$ not significant; $C V=$ coefficient of variation.

Para a variável vagem por planta, não houve diferenças significativas em ambos os anos, porém destaca-se o maior resultado obtido, no primeiro ano, referente à linhagem CNFC 10729 com 13 vagens por planta e, no segundo ano, referente ao cultivar IAC Alvorada com 
18 vagens por planta. Os piores resultados obtidos pertencem ao cultivar BRS Notável com uma média de 7 vagens por planta, e à linhagem CNFP 10794 com aproximadamente 6 vagens por planta, no primeiro e segundo ano, respectivamente.

Quanto à variável grãos planta-1 ${ }^{1}$ apresentou variações significativas no primeiro ano, no qual o cultivar BRS Esplendor e a linhagem CNFP 10794 destacaram-se com média de 66 grãos por planta. Contudo, mesmo não havendo diferenças significativas, no segundo ano a linhagem CNFC 10729 conseguiu o melhor resultado com média de 84 grãos por planta. O pior desempenho, no primeiro ano, foi obtido pelo cultivar BRS Notável com aproximadamente 30 grãos por planta e, no segundo ano, pelo cultivar CNFP 10794 com 32 grãos por planta.

Tabela 1. Valores médios da massa de 100 grãos e produtividade de grãos dos diferentes genótipos de feijão comum. Selvíria - MS, 2014 e 2015. Mean values of the 100 grain mass and grain yield of the different common bean genotypes. Selviria - MS, 2014 and 2015.

\begin{tabular}{ccccc}
\hline Tratamentos & \multicolumn{2}{c}{ Massa de 100 grãos } & \multicolumn{2}{c}{ Produtividade } \\
\hline Genótipos & 2014 & 2015 & 2014 & 2015 \\
\hline BRS Ametista & $29,47 \mathrm{~b}$ & $30,19 \mathrm{a}$ & $2.789 \mathrm{~b}$ & $3.305 \mathrm{a}$ \\
BRS Campeiro & $27,19 \mathrm{c}$ & $27,25 \mathrm{~b}$ & $3.189 \mathrm{a}$ & $2.634 \mathrm{~b}$ \\
BRS Esplendor & $23,82 \mathrm{~d}$ & $20,74 \mathrm{~d}$ & $2.989 \mathrm{a}$ & $2.688 \mathrm{a}$ \\
BRS Esteio & $28,75 \mathrm{~b}$ & $24,46 \mathrm{c}$ & $3.396 \mathrm{a}$ & $2.604 \mathrm{~b}$ \\
BRS Estilo & $30,69 \mathrm{~b}$ & $27,59 \mathrm{~b}$ & $2.698 \mathrm{~b}$ & $2.206 \mathrm{~b}$ \\
BRS Notável & $25,83 \mathrm{c}$ & $24,52 \mathrm{c}$ & $2.694 \mathrm{~b}$ & $2.553 \mathrm{~b}$ \\
BRSMG Madrepérola & $24,33 \mathrm{c}$ & $26,97 \mathrm{~b}$ & $2.338 \mathrm{c}$ & $2.364 \mathrm{~b}$ \\
IAC Alvorada & $36,36 \mathrm{a}$ & $29,51 \mathrm{a}$ & $2.796 \mathrm{~b}$ & $1.878 \mathrm{~b}$ \\
IAC Diplomata & $22,54 \mathrm{~d}$ & $23,25 \mathrm{c}$ & $2.670 \mathrm{~b}$ & $2.204 \mathrm{~b}$ \\
IAPAR 81 & $26,02 \mathrm{c}$ & $25,92 \mathrm{~b}$ & $2.831 \mathrm{~b}$ & $2.212 \mathrm{~b}$ \\
IPR Tangará & $28,04 \mathrm{~b}$ & $26,41 \mathrm{~b}$ & $2.838 \mathrm{~b}$ & $3.228 \mathrm{a}$ \\
Pérola & $25,52 \mathrm{c}$ & $29,53 \mathrm{a}$ & $2.187 \mathrm{c}$ & $2.363 \mathrm{~b}$ \\
TAA Bola Cheia & $21,00 \mathrm{~d}$ & $27,00 \mathrm{~b}$ & $510 \mathrm{~d}$ & $2.491 \mathrm{~b}$ \\
CNFC 10429 & $30,72 \mathrm{~b}$ & $26,28 \mathrm{~b}$ & $2.855 \mathrm{~b}$ & $2.282 \mathrm{~b}$ \\
CNFC 10729 & $31,94 \mathrm{~b}$ & $28,29 \mathrm{a}$ & $3.152 \mathrm{a}$ & $2.307 \mathrm{~b}$ \\
CNFC 10762 & $27,89 \mathrm{~b}$ & $26,56 \mathrm{~b}$ & $3.354 \mathrm{a}$ & $2.859 \mathrm{a}$ \\
CNFP 10794 & $25,74 \mathrm{c}$ & $27,03 \mathrm{~b}$ & $3.137 \mathrm{a}$ & $2.841 \mathrm{a}$ \\
\hline Teste F & $10,83 * *$ & $16,00 * *$ & $13,46 * *$ & $2,60 * *$ \\
\hline CV $(\%)$ & 7,23 & 3,86 & 11,34 & 15,88 \\
\hline
\end{tabular}

Médias seguidas de mesma letra, dentro de cada safra estudada, não diferem entre si pelo teste de Scott-Knott a $6 \%$ de probabilidade. $*{ }^{*},=$ significativo a $6 \%$ e $1 \%$ de probabilidade pelo teste de Scott-Knott, respectivamente; NS = não significativo; $\mathrm{CV}=$ coeficiente de variação. Means followed by the same letter, within each crop studied, do not differ among themselves by the Scott-Knott test at 6\% probability. *, ** = significant at $6 \%$ and $1 \%$ probability by the Scott-Knott test, respectively; $N S=$ not significant; $C V=$ coefficient of variation.

Em relação ao número de grãos por vagem, somente no primeiro ano houve diferenças significativas entre os tratamentos. Destes, os cultivares que mais se destacaram nesse quesito, 
no primeiro e segundo ano, foram o BRS Esteio a linhagem CNFC 10429, respectivamente, ambos com aproximadamente 6 grãos por vagem, enquanto o menor desempenho foi do cultivar IAC Alvorada em ambos os anos com aproximadamente 4 e 3 grãos por vagem, respectivamente.

Os resultados referentes às variáveis apresentadas corroboram aos apresentados por Sousa et al. (2014) que, ao avaliar características agronômicas e resistência de genótipos de feijão comum no estado do Tocantins, obtiveram resultados semelhantes sendo para número de grãos por vagem e número de vagens por planta5,1 e 12,8 respectivamente para linhagem CNFP-10794 e 4,5 e 14 para o cultivar BRS Esplendor.

Como é possível observar na Tabela 4, houve diferenças significativas para as variáveis massa de 100 grãos e produtividade de grãos nos dois anos de cultivo

Para a massa de 100 grãos o maior valor foi do IAC Alvorada (36,36 g), seguido das linhagens CNFC 10729 (31,94 g) e CNFC 10429 (30,72 g) no primeiro ano. No ano seguinte foram BRS Ametista (30,19 g), seguida dos cultivares Pérola (29,53 g) e IAC Alvorada $(29,51 \mathrm{~g})$ e os piores resultados foram do cultivar TAA Bola Cheia $(21,0 \mathrm{~g})$ e BRS Esplendor $(20,74 \mathrm{~g})$, respectivamente.

Vários autores, incluindo Souza (2006) destacam que a massa das sementes é uma variável que influencia na escolha do cultivar que pode ser utilizada, visto que devido ao peso pode variar o custo de produção por área, possibilitando também outros fatores como maior volume de comercialização e maior velocidade nos processos de germinação e emergência. Contudo alguns autores apontam que esta é uma variável pouco influenciada pelos diferentes ambientes de cultivo em razão de ser uma herança qualitativa e controlada por poucos genes ou que os componentes de produção, de forma isolada, não influem no rendimento final de grãos (FAGERIA et al., 2006; ZILIO et al., 2011).

Os dados deste experimento confirmam esta hipótese, exemplo do cultivar Esplendor que, mesmo, apresentando os menores valores de massa de 100 grãos, sobressaiu-se em grãos planta- ${ }^{1}$, grãos vagem- ${ }^{1}$ e produtividade em ambos os anos. Assim como Bezerra et al. (2007) que em seu experimento com feijão-caupi (Vigna unguiculata) obteve diferenças significativas no rendimento de grãos decorrente da modificação no espaçamento de plantas, independente dos componentes de produção não terem apresentado diferenças.

Quanto à produtividade, o cultivar BRS Esteio (3.396 $\mathrm{kg} \mathrm{ha}^{-1}$ ) e a linhagem CNFC 10762 (3.354 kg ha $\left.{ }^{-1}\right)$ sobressaíram, no primeiro ano, em relação aos demais. Por outro lado, no segundo ano, o cultivar BRS Ametista (3.305 kg ha-1), seguido do IPR Tangará (3.228 kg $\mathrm{ha}^{-1}$ ) destacaram-se em relação à mesma variável. Ainda referente à produtividade, o cultivar TAA Bola Cheia (510 $\left.\mathrm{kg} \mathrm{ha}^{-1}\right)$ apresentou o menor desempenho, no primeiro ano, na qual esta queda de produtividade foi atribuída ao desenvolvimento da doença antracnose. Já, no o segundo ano, o cultivar IAC Alvorada (1.878 $\left.\mathrm{kg} \mathrm{ha}^{-1}\right)$ apresentou o menor valor.

De acordo com o catálogo da Embrapa safra 2016/17, o cultivar Pérola tem potencial produtivo de, em média, $3.903 \mathrm{~kg} \mathrm{ha}^{-1}$, contudo a partir do resultado obtido pode-se notar que este máximo potencial dificilmente será obtido na região de produção em questão, uma vez que a maior produtividade foi de $2.363 \mathrm{~kg} \mathrm{ha}^{-1}$. 
Ao reputar as tabelas que fornecem os dados relativos aos cultivares, foi possível notar que alguns fatores influenciaram na produtividade desses cultivares e linhagens como, por exemplo, a antracnose no cultivar TAA Bola cheia no primeiro ano. Segundo a literatura, esta doença pode promover perdas de até $100 \%$ da produtividade se manifestada no início da cultura e, além disso, pode gerar depreciações na qualidade dos grãos. Pelúzio et al. (2002) afirma que uma redução na disponibilidade de fotoassimilados para o enchimento das vagens, pode provocar uma redução nessa característica e, Navarro Júnior e Costa (2002), complementam ao afirmarem a relevância que deve-se ser dada à fase de formação de vagens, pois esta pode ser prejudicada em razão da competição por fotoassimilados com as vagens formadas mais cedo, e pode limitar fisicamente o tamanho potencial do grão.

O número de vagens por planta, o número de grãos por vagem e a massa de grãos são variáveis intrínsecas à produtividade, ou seja, indispensáveis na seleção de genótipos produtivos. É importante salientar que se caso um desses componentes seja prejudicado durante o desenvolvimento da planta, outro componente se eleva, estabilizando a produtividade (COSTA et al., 1983; COIMBRA et al., 1999).

A partir dos resultados obtidos é possível observar que nem sempre os melhores cultivares e linhagens, em relação à produtividade, são aquelas com melhores desempenhos sobre alguma variável de produção, pois estas estão associadas ao o resultado final de rendimento, corroborando o pensamento de alguns autores como Fageria et al. (2006).

Considerando a média de produtividade dos dois anos de produção, a linhagem CNFC 10762, seguida dos cultivares BRS Ametista, IPR Tangará e BRS Esteio apresentaram os melhores desempenhos. Todas as linhagens alcançaram médias maiores que a testemunha Pérola, o que corrobora os resultados obtido por Pontes Júnior et al. (2009).

\section{CONCLUSÃO}

Nos dois anos de cultivo, os genótipos CNFC 10762, CNFC 10729 e CNFP 10794, apresentaram bom comportamento na região, logo boa perspectiva de serem lançados como novos cultivares.

A suscetibilidade para a doença antracnose do cultivar TAA Bola Cheia desaconselha a utilização do mesmo na região estudada.

A presença de interação genótipo x ambiente indica a necessidade a avaliação dos genótipos em vários anos e locais.

\section{AGRADECIMENTOS}

À EMBRAPA Agropecuária Oeste (Dourados) pelo fornecimento das sementes utilizadas no desenvolvimento do trabalho 


\section{REFERÊNCIAS BIBLIOGRÁFICAS}

ALLARD, R. W.; BRADSHAW, A. D. Implications of genotype environment interactions in applied plant breeding. Crop Science, Madison, v. 4, n. 5, p.503-508, 1964.

AMBROSANO, E. J.; WUTKE, E. B.; BULISANI, E.; CATARELLA, H. Feijão. In: RAIJ, B. van, CANTARELlA, H.; QUAGGIO, J. A.; FURLANI, A. M. C. Recomendações de adubação e calagem para o Estado de São Paulo. 2. ed. Campinas: IAC, 1996. cap. 19, p.194-195. (Boletim Técnico 100).

BEZERRA, A. P. A.; PITOMBEIRA, J. B.; TÁVORA, F. J. A. F.; VIDAL NETO, F. C. Rendimento, componentes da produção e uso eficiente da terra nos consórcios sorgo $\mathrm{x}$ feijãode-corda e sorgo x milho. Revista Ciência Agronômica, Fortaleza v. 38, n. 1, p.104-108, 2007.

BRASIL. Ministério da Agricultura. Regras para análise de sementes. Brasília, DNPV/DISEM, 1980. 188 p.

CARNEIRO, J. E. S. Alternativas para obtenção e escolha de populações segregantes no feijoeiro. 2002. 134 p. Tese (Doutorado em Genética e Melhoramento de Plantas) Universidade Federal de Lavras, Lavras 2002.

COIMBRA, J. L. M.; CARVALHO, F. I. F.; HEMP, S.; SILVA, S. A. Adaptabilidade e estabilidade de fenotípica em genótipos de feijão de cor (Phaseolus vulgarisL.) em três ambientes distintos. Ciência Rural, Santa Maria, v. 29, n. 3, p.441-448, 1999.

COIMBRA, J. L. M.; BERTOLDO, J. G.; EliAS, H. T.; HEMP, S.; VALEI, N. M.; TOALDO, D.; ROCHA, F.; BARILI, L. D.; GARCIA, S. H.; GUIDOLINI, A. F.; KOPP, M. M. Mineração da interação genótipo x ambiente em Phaseolus vulgaris L. para o Estado de Santa Catarina. Ciência Rural, Santa Maria, v. 39, n. 2, p.355-363, 2009.

COMPANHIA NACIONAL DE ABASTECIMENTO - CONAB. Observatório agrícola, acompanhamento da safra brasileira de grãos: safra 2017/2018. Brasília, v. 5, n. 9, p.6890, 2018.

COSTA, J. G. C.; KOHASHI-SHIBATA, J.; COLIN, S. M. Plasticidade no feijoeiro comum. Pesquisa Agropecuária Brasileira, Brasília, v. 18, n.2, p.159-167, 1983.

EMPRESA BRASILEIRA DE PESQUISA AGROPECUÁRIA - EMBRAPA. Informações técnicas para o cultivo do feijoeiro comum na região nordeste brasileira. In: 17 $^{\mathrm{a}}$ Reunião da Comissão Técnica Norte/Nordeste Brasileira de Feijão (Aracaju - SE). 2012-2014. 21. ed. Aracaju: EMBRAPA TABULEIRO COSTEIRO, 2013. 199 p. (Embrapa Tabuleiro Costeiro. Documentos, 181).

EMPRESA BRASILEIRA DE PESQUISA AGROPECUÁRIA - EMBRAPA. Centro Nacional de Pesquisa de Solos. Sistema brasileiro de classificação de solos. 3. ed. Brasília: EMBRAPA / Centro Nacional de Pesquisa de Solos, 2013. 353 p.

FAGERIA, N. K.; BALIGAR, V. C.; CLARK, R. B. Physiology of crop production. New York: Food Products, 2006. 345 p. 
MELO, L. C.; MELO, P. G. S.; FARIA, L. C.; DIAZ, J. L. C.; PELOSO, M. J.; RAVA, C. A.; COSTA, J. G. C. Interação com ambientes e estabilidade de genótipos de feijoeiro-comum na Região Centro-Sul do Brasil. Pesquisa Agropecuária Brasileira, Brasília, DF, v. 42, n. 5, p.715-723, 2007.

NAVARRO JUNIOR, H. M.; COSTA, J. A. Contribuição relativa dos componentes do rendimento para produção de grãos em soja. Pesquisa Agropecuária Brasileira, Brasília, DF, v. 37, n. 3, p.269-274, 2002.

PELÚZIO, J. M.; BARROS, H. B.; ROCHA, R. N. C.; SILVA, R. R.; NASCIMENTO, I. R. Influência do desfolhamento artificial no rendimento de grãos e componentes de produção da soja [Glycinemax (L.) Merrill]. Ciência Agrotecnológica, Lavras, v. 26, n. 6, p.1197-1203, 2002.

PEREIRA, H. S.; MELO, L. C.; FARIA, L. C.; PELOSO, M. J.; COSTA, J. G. C.; RAVA, C. A.; WENDLAND, A. Adaptabilidade e estabilidade de genótipos de feijoeiro-comum com grãos tipo carioca na Região Central do Brasil. Pesquisa Agropecuária Brasileira, Brasília, DF, v. 44, n. 1, p.29-37, 2009

PEREIRA, H. S.; MElO, L. C.; WENDlAND, A.; PElOSO, M. J.; FARIA, L. C.; NASCENTE, A. S.; DÍAZ, J. L. C.; COSTA, J. G. C.; CARVALHO, H. W. L.; COSTA, A. F.; AlMEIDA, V. M.; MELO, C. L. P.; MAGALDI, M. C. S.; ABREU, A. F. B.; MOREIRA, J. A. A.; FILHO, I. A. P.; CARGNIN, A.; POSSE, S. C. P.; FILHO, B. F. S.; NETO, F. P. M.; GUIMARÃES, C. M.; BRAZ, A. J. B. P.; FERREIRA, S. B. MARANGON, M. A.; SOUZA, N. P.; OLIVEIRA, J. P.; FARIA, J. C.; BASSINELLO, P. Z. BRS Esteio: cultivar de feijoeiro comum com grãos pretos, alto potencial produtivo e resistência à antracnose. Santo Antônio de Goiás: Embrapa arroz e feijão, 2013. 4 p. (Embrapa arroz e feijão. Comunicado técnico 213)

PONTES JÚNIOR, V. A; MELO, L. C.; PEREIRA, H. S.; FARIA, L. C.; COSTA, J. G. C., WENDLAND, A.; DEL PELOSO, M. J. Estabilidade de genótipos de feijoeiro comum no estado de goiás para produtividade de grãos, ciclo 2007/2008. In: CONGRESSO DE PESQUISA, ENSINO E EXTENSÃO: Ciência e desenvolvimento regional, 6, 2009, Goiânia. Anais [...] Goiânia: Universidade Federal do Goiás, 2009. p. 5023-5027.

RAIJ, B. van; ANDRADE, J. C.; CANTARElla, H.; QUAGGiO, J. A. (ed.). Analise química para avaliação da fertilidade de solos tropicais. Campinas: Instituto Agronômico, 2001. cap. 17 , p. 251-261

SOUSA, S. A.; OLIVEIRA, T. C.; GONÇALVES, G. M. O.; LOPES, M. B. S.; SANTOS, G. R.; FIDELIS, R. R. Características agronômicas e resistência de genótipos de feijão comum à mela no sul do Estado do Tocantins. Journal of Biotechnology and Biodiversity, Gurupi, v. 5, n. 2, p.130-139, 2014.

SOUZA, E. L. Qualidade de sementes de soja comercializadas pela cooperative agroindustrial COPAGRIL no Paraná. 2006. 34 p. (Dissertação mestrado em Ciência e Tecnologia de Sementes) - Universidade Federal de Pelotas. Pelotas, 2006. 
SOUZA, T. L. P. O.; PEREIRA, H. S.; FARIA, L. C.; WENDLAND, A; COSTA, J. G. C.; ABREU, A. F. B.; DIAS, J. L. C.; MAGALDI, M. C. S; SOUZA, N. P.; PELOSO, M.J.; MELO, L. C. Cultivares de feijão comum da Embrapa e parceiros disponíveis para 2013. Santo Antônio de Goiás: Embrapa arroz e feijão. 2013, 6 p. (Embrapa Arroz e Feijão. Comunicado Técnico 211).

VIEIRA, C.; PAULA JÚNIOR, T. J.; BORÉM, A. (ed.) Feijão. 2. ed. amp. rev. Viçosa, MG: Editora UFV, 2006. 600 p.

ZILIO, M.; COELHO, C. M. M.; SOUZA, C. A.; SANTOS, J. C. P.; MIQUELLUTI, D. J. Contribuição dos componentes de rendimento na produtividade de genótipos crioulos de feijão (Phaseolus vulgaris L.). Revista Ciência Agronômica, Fortaleza, v. 42, n. 2, p.429438, 2011. 